\title{
Analysis on the Influence of Geographical Indication Protection on International Competitiveness of Shaanxi Apple
}

\author{
Xiaowei Zhou; Xinyin Zhang; Junnan Dong \\ Shaanxi Normal University \\ Email:524948616@qq.com
}

\begin{abstract}
As a big agricultural province in western China, Shaanxi loess plateau area of Weibei has a unique ecological environment and natural climate, and the climate here is the only one that meets the requirements of seven indicators for apple growth. In 2003, after Shaanxi's apple got the geographical indication protection products, it got an unprecedented development, that is, the Shaanxi apple cultivation area and yield became the first in the nation, and its production accounts for about a third of the country, $11 \%$ of the world. Shaanxi apple industry is the pillar industry of the whole province's national economy development, which occupies the important position in the national apple industry. With Shaanxi apple approved geographical indication products and the development of economic globalization, for Shaanxi's apple industry, how to make use of the geographical indication brands to sell apple outside the province and to improve international competitiveness of these brands in the fierce international competition to maintain the steady development is of a subject worthy of our study. Based on the international market share, revealed comparative advantage indexes of theoretical basis, the author analyzes the international competitiveness of Shaanxi apple industry before and after it got the geographical indication protection.
\end{abstract}

Keywords-Shaanxi apple industry; Geographical indication protection; International competitiveness

\section{INTRODUCTION}

\section{A. Research background}

China joined the WTO in 2001, and has been fully involved in the process of economic globalization since then. In this stage, China will have more agricultural products entering the international market, and compete fairly with foreign corresponding agricultural products to share the market share. And the agricultural products with geographical signs in the international agricultural products market competition undoubtedly has the force that cannot be ignored.

As a member of the WTO, China's application for certification of geographical indications for various products is relatively backward, but it has developed rapidly. In 2005, Chinese geographical indications research group conducted a survey on 323 products with geographical indications certification, of which 307 were agricultural products, accounting for about $95 \%$ of the total. Agricultural products trade approved for geographical indications is a very important part of international trade and is closely linked with agriculture, rural areas and farmers.

\section{B. Domestic and foreign literature review}

Developed countries started to certify and protect geographical indications products and have strict requirements on the protection of intellectual property rights long before. In 1900, France had already formulated laws and regulations to strengthen the protection of geographical indications. Later, other countries in the world also formulated and improved relevant laws and regulations.

Bruce Babcock (2004) [1] studied several countries on the protection of geographical indication products' difference, and expounds the United States, the European Union and the WTO impact on the different products of geographical indications protection mechanism of competitiveness of agricultural products, Bruce Babcock say the United States for the protection of geographical indication product brand is relatively weak.

The certification and protection of geographical indications products started late in China. The trademark law of 2001 stipulates for the first time that geographical indications products should be protected.

About the research on laws and regulations of geographical indications of agricultural products level, Xiaoping Zhao(2007) [2] studied the development of the geographical indication protection, in the member states of the WTO rules and the next about strengthening the practice of geographical indication protection work; The importance attached by the European Community and the regional trade agreement (RTA) to the protection of geographical indications products and the relevant legislation in China. Furong Tian(2008) [3]defined the law of the geographical indication of belonging, and studied the law for the protection of geographical indication products at home and abroad and legislative issues, hereby put forward the law of our country to protect geographical indication system framework. 


\section{THE CONNOTATION AND CHARACTERISTICS OF GEOGRAPHICAL INDICATIONS}

Geographical indication is accompanied by the continuous development of marks of origin, name of origin and generated. In 1994, the WTO in the trade-related intellectual property agreement, roughly defined the concept of geographical indication, prescribed in paragraph 1 of article 22: the geographical indication that a certain goods is derived from the territory or within the territory of a member of a certain area, and the goods quality, reputation or other characteristics are associated with the geographical origin.

According to the international market share (MS) in table 4-1, although the MS value of Shaanxi fresh apple is small, its overall market share is increasing, from $0.16 \%$ in 2003 to $0.57 \%$ in 2014, more than three times. China's fresh apple MS more than tripled from 6.04 percent in 2003 to 15.24 percent in 2014. Can be seen from the figure 4-2, Shaanxi fresh apple exports accounted for the proportion of China's fresh apple exports volatility is larger, and the ratio is small, mainly because of Shaanxi apple export trade mainly in the form of concentrated apple juice products in international trade, fresh apple exports less, but also demonstrates the whole Shaanxi apple industry with strong competitiveness in the international trade of agricultural products.

\section{A. Revealed Comparative Advantages}

Revealed Comparative Advantage (RCA) index refers to a country or region a commodity exports accounted for the country or regional total exports and the global this kind of merchandise exports accounted for the ratio of the world's total exports. Display comparative advantage index is one of the most influential indexes to measure the international competitiveness of a product. The formula is: $R C A_{\mathrm{ij}}=\left(X_{\mathrm{ij}} / X_{\mathrm{nj}}\right) \div\left(X_{\mathrm{iw}} / X_{n w}\right), X_{i j}$ represents the exports of country $\mathrm{j}$ or region $\mathrm{j}$ to product $\mathrm{i}, X_{n j}$ represents the total exports of country $\mathrm{j}$ or region $\mathrm{j}, X_{i w}$ represents the total exports of global product i, $X_{n w}$ and represents the total global exports.

If $\mathrm{RCA}<1$, It indicates that the product has no comparative advantage in international market competition, that is, the product has a weak international competitiveness.

If RCA > 1, It show that the products in their home country or the region's export ratio is greater than the export proportion in the whole world, there are certain international competitiveness, this product has advantages in the international market competition.

If the value of RCA rises, it indicates that the export competitiveness of product $\mathrm{i}$ is rising and the comparative advantage is gradually strengthened.

As can be seen from table 4-1, the RCA index of fresh apples in Shaanxi has been rising rapidly since 2003. In particular, in 2006, 2010, 2012 and 2014, the RCA value was greater than 9, indicating that Shaanxi fresh apples have a strong international competitiveness. Since the geographic marks of Shaanxi apple approved, RCA index increased from 6.79 in 2003 to 12.55 in 2014,2008 , the main reason for the smaller numerical is affected by the international market, especially the global financial crisis in 2008 in Shaanxi province fresh apple export trade has caused negative influence greatly. As can be seen from figure 4-2, in recent years, the RCA value of fresh apples in China has shown a slight upward trend on the whole. RCA acuity 1.25 since 2010, the international competitiveness of China's fresh apple has improved, but China's fresh apple RCA value is far lower than the fresh apple RCA numerical Shaanxi, Shaanxi fresh apple export competitiveness and China's overall, compared to fresh apple export competitiveness has more advantages.

TABLE I RCA AND MS OF SHAANXI FRESH APPLES AND CHINESE FRESH APPLES

RCA

$\begin{array}{lll}\text { year } & \text { Shaanxi } & \text { China } \\ 1998 & 0.79 & 0.98 \\ 2000 & 3.35 & 1.06 \\ 2002 & 4.22 & 1.04 \\ 2003 & 6.79 & 1.03 \\ 2004 & 7.95 & 1.09 \\ 2006 & 9.39 & 1.04 \\ 2008 & 6.74 & 1.24 \\ 2010 & 9.37 & 1.37 \\ 2012 & 16.38 & 1.38 \\ 2014 & 12.55 & 1.25\end{array}$

MS

$\begin{array}{ll}\text { Shaanxi } & \text { China } \\ 0.11 \% & 3.36 \% \\ 0.13 \% & 4.24 \% \\ 0.11 \% & 5.26 \% \\ 0.16 \% & 6.04 \% \\ 0.21 \% & 7.04 \% \\ 0.28 \% & 8.30 \% \\ 0.34 \% & 11.01 \% \\ 0.35 \% & 14.26 \% \\ 0.72 \% & 14.36 \% \\ 0.57 \% & 15.24 \%\end{array}$




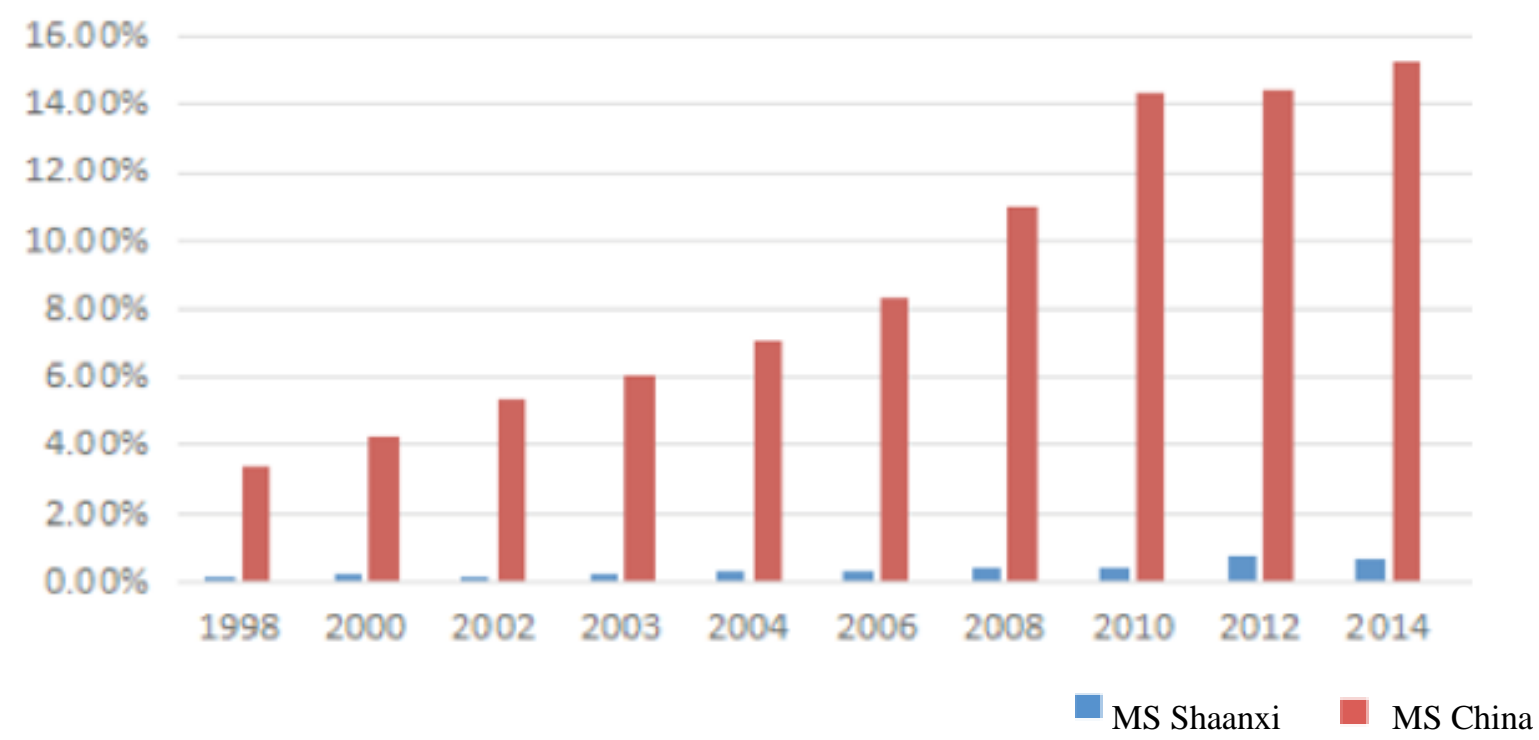

Fig. 1 MS index of fresh apples in Shaanxi and fresh apples in China

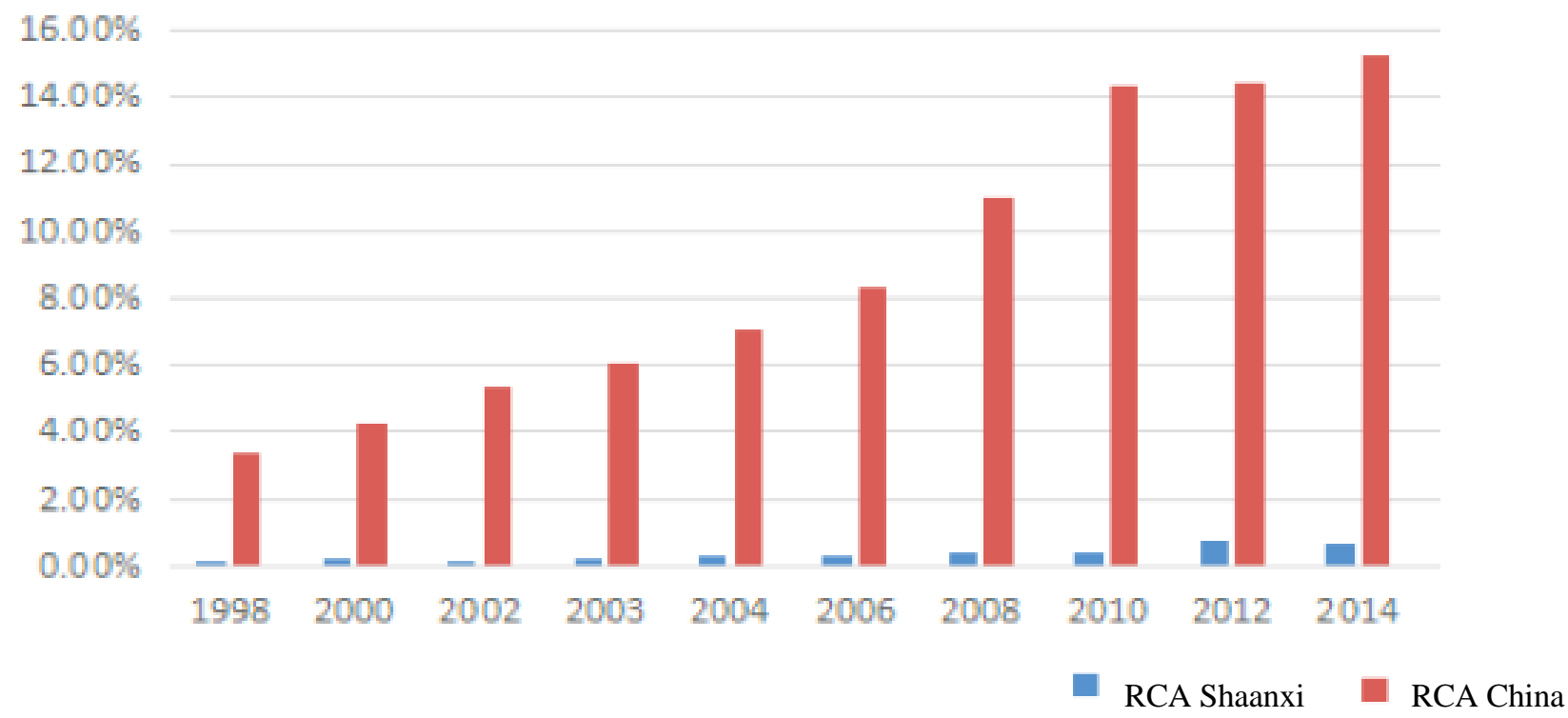

Fig. 2 RCA index of fresh apples in Shaanxi and fresh apples in China

\section{GEOGRAPHICAL INDICATION PROTECTION EFFECT MECHANISM OF SHAANXI APPLE'S INTERNATIONAL COMPETITIVENESS}

As apples are agricultural products, and agricultural products trade in the international market competition is very fierce, therefore, Shaanxi apples are also facing great competitive pressure in export. It can be seen from the foregoing that international competitiveness refers to the ability of a kind of agricultural products of a certain country to enter the international competition and continuously obtain profits, which is mainly determined by the brand, quality and price.

\section{A. Promote Shaanxi apple quality standardization}

Chinese general administration of quality supervision, inspection and quarantine pointed out that goods that have

been designated as geographical indications should not only be produced in specific regions, but also meet national standards. Therefore, the successful application of Shaanxi apple for geographical indications has greatly improved its quality. After applying for the protection of geographical indications, the Shaanxi provincial government improved the overall quality of apples in Shaanxi from various aspects, such as improving the soil for planting apples. The water quality of irrigated fruit trees was optimized. To rectify the use of pesticides, fertilizers and other related products; Strengthen the pest control of fruit trees, establish ecological orchards, in order to cultivate green and high-quality apples. Through a series of efforts, the rate of high quality fruit in Shaanxi apple orchard has been greatly 
improved, and the quality standard of some apples has far exceeded the national standard.

\section{B. Promote the industrialization of Shaanxi apple production}

Shaanxi apple in the loess plateau of Wei River this specific region on the basis of the production base, production results be Shared the regional apple producers, foreign enterprises to use the geographical indication, only in local production investment, which makes the development of Shaanxi apple industry more concentrated. Secondly, Shaanxi apple implements the national unified standard, standardizes and centralizes the quality apple of decentralized operation, and constructs the scale economy effect. At present, Shaanxi plant and cultivate high quality fruit tree to introduce the "geographical indication + leading enterprises + farmers" integration model, the peasant household, enterprise resources and government resources optimization combination, promote Shaanxi apple on the path of industrialization.

\section{Accelerate the brand promotion of Shaanxi apple geographical indications}

At present, Shaanxi apple this brand products of geographical indications is not implemented a household name, but the geographical indication products due to its unique geographical cultural conditions with high recognition in the international market, which for the establishment of Shaanxi apple brand laid a solid foundation. The provincial government as long as the relative protection of Shaanxi apple trumpeted, and export to various aspects of this province apple support, implement the strategy of apple industry chain, is bound to the fierce competition in the international market to take certain share.

\section{CONCLUSION}

Shaanxi apple as comprehensive value in the protection of geographical indications in China the first agricultural products, its international competitiveness in the approved geographical indications show great differences before and after, after 2003, Shaanxi apple exports and international competitiveness significantly increased. Approved the reasons for the success of geographical indications of Shaanxi apple basically has: Shaanxi provincial government fully tap the local unique geographical resources advantage, strengthen the support and guidance of the apple industry, to realize apple industrialization chain, etc. In a word, the Shaanxi authorities are trying their best to promote and realize the internationalization of Shaanxi apple brand.

This paper calculates the international competitiveness of related index of geographical indication influence the international competitive power of Shaanxi apple effect is analyzed, and on the basis of the export data in recent years Shaanxi apple analyzed the dynamic change of its international competitiveness.

It can be seen from the text that Shaanxi apple has benefited from the importance of geographical indications in international agricultural product market transactions. The role of geographical symbol protection in enhancing international competitiveness of Shaanxi apple is mainly reflected in unique geographical resource conditions and reliable quality standards.

\section{REFERENCES}

[1] Bruce A. Babcock. Roxanne Clemens Geographical Indications and Property Rights: Protecting Value-Added Agricultural Products [MATRIC Briefing Paper 04-MBP 7] 2004

[2] Xiaoping Zhao. Study on legal protection of geographical indications. Beijing: law press, 2007

[3] Furong Tian. Study on the legal protection system of geographical indications. Beijing: intellectual property press, 2009

[4] Qiming Deng, Dongping Zhu, Xiuyun Dong, Deping Xiong. Geographical indication protection, the special advantage industries development and agricultural product international competitiveness research one by one based on the investigation and analysis of Fujian and Zhejiang provinces [J]. Journal of agricultural economy, 2011 (9): 47-52.

[5] Huazun Huang. Protection of intellectual property rights in agricultural modernization and geographical indications. Legal research, 2006, $1: 103-105$

[6] Hua Li, Zhaoke Wang. The essential difference between geographical indications and trademarks. World agriculture, 2006, 1(321): 48-51

[7] Xiaohong Liu. Operation analysis of Shaanxi agricultural industrialization leading enterprise [J]. Township economy. 2006(7)

[8] Weichao Lv. A systematic insight into the productive forces derived from "tradition" and "culture" -- the path choice of the protection of geographical symbols in China. Theory and reform, 2007,6

[9] Enhu Wang. Problems and countermeasures in the development of Shaanxi characteristic agriculture [J]. Journal of Shaanxi University of Administration and Shaanxi University of economic cadre management, 2005(8).

[10] Xitao Zhang. Analysis on the impact of applying geographical indications on the economic benefits of agricultural products -- a case study of Shaanxi apple [D]. Master's thesis of Nanjing Agricultural University, 2007.5.

[11] [Michael Blakeney.2011.Geographical indications and the Marketing of Agricultural products: Mauritius-a case study. International Trade Law and Regulationl7 (2), 58-69. 